\title{
Carta del Padre Provincial de España de la Compañía de Jesús sobre la Revista de Fomento Social
}

22 Abril 2014

P. Ildefonso Camacho, S.I.

Presidente

Fundación Universidad Loyola Andalucía

Querido Ildefonso:

Por la presente contesto a tu petición del pasado 25 de enero que me realizabas como Presidente del Patronato de la Fundación Universidad Loyola Andalucía.

Con agradecimiento apruebo la actualización del encargo que, en su tiempo, recibió ETEA respecto a la Revista de Fomento Social. En las nuevas circunstancias sería la Universidad Loyola Andalucía quien asuma aquel compromiso en los mismos términos que se ha venido haciendo hasta ahora.

Estoy seguro de que la Revista continuará aportando perspectiva y profundidad sobre las cuestiones del campo social que actualmente preocupan a nuestra sociedad.

Con todo mi afecto en el Señor,

Francisco José Ruiz Pérez, S.I.

Provincial de España 